\title{
Reconstruction of the Upper Eyelid with Flaps and Free Grafts after Excision of Basal Cell Carcinoma
}

\author{
Alessandro Guido Actis ${ }^{a}$ Gianpiero Actis $^{b}$ \\ ${ }^{a}$ Eye Clinic, Ophthalmic Section, Department of Clinical Physiopathology, \\ University of Turin, and ${ }^{b}$ Ophthalmic Hospital of Turin - ASL 1, Turin, Italy
}

\section{Key Words}

Ophthalmoplastic surgery $\cdot$ Basal cell carcinoma $\cdot$ Eyelid $\cdot$ Graft $\cdot$ Flap

\begin{abstract}
Purpose: To describe a reconstructive technique of the superior eyelid with flaps and free grafts after excision of a basal cell carcinoma.
\end{abstract}

Methods: Single case report of a 79-year-old woman who presented to our hospital with a basal cell carcinoma of the upper eyelid margin with initial erosion.

Results: A large and full-thickness excision of the carcinoma was performed. The reconstruction technique should be customized to the individual patient. In this case, the use of a full-thickness tarsal graft from the contralateral upper eyelid, followed by an ipsilateral bipedicled flap and finally by a skin graft, was an effective surgical procedure, performed in one stage, without complications, and with good functional and esthetic results.

Conclusions: Malignant neoplasms represent the leading cause of plastic reconstruction in the orbital region. Surgical techniques must be individualized for each patient and for each type of carcinoma. Reconstructive techniques with free grafts and flaps yield excellent results in the orbital region, particularly when some advice and a few fundamental rules are followed, namely accurate hemostasis of the receiving graft bed by moderate use of diathermy, careful suturing of the edges, and application of a compressive dressing for at least 4 days. Postoperative complications are very rare.

\section{Introduction}

Malignant neoplasms represent the leading cause of plastic reconstruction in the orbital region, followed by cicatricial retraction, post-traumatic tissue loss and congenital colobomas $[1,2]$. 
Approximately 5-10\% of all skin cancers occur in the eyelid [3]. Incidence studies indicate that basal cell carcinoma is the most frequent malignant eyelid tumor, followed by squamous cell carcinoma, sebaceous gland carcinoma and malignant melanoma. These eyelid malignancies represent the main reason for eyelid reconstruction in ophthalmoplastic surgery $[3,4]$.

Considering comparable studies in the literature, we were able to find two level-A recommendations for basal cell carcinoma, squamous cell carcinoma, and sebaceous gland carcinoma: the use of Mohs micrographic surgery or excision with frozen-section control [5]. Immediate reconstruction, with previous sending of the tumor's critical margins to anatomopathological service (permanent sections), can only be managed in the following few cases [5-8]: (1) if a cancer recurrence is not being treated, (2) if the tumor is not infiltrative, the borders are well delimited and if it is not localized at the internal canthus, (3) if the basal cell carcinoma can be excised with a wide margin (at least $4 \mathrm{~mm}$ of skin clearance), and (4) in older patients with high anesthesiological risk.

Immediate reconstruction can lead to optimal healing because the granulation process has not yet initiated. If the anatomopathological response is still positive, the patient can be carefully supervised or just the positive area can be immediately reoperated $[5,7]$.

In malignant neoplasms affecting the orbital region of the eyelids, deeper tissues may be involved to a considerable degree, and the tumor may sometimes extend down to bone. Though this may not be the case with basal cell carcinoma, it is often true of infiltrating squamous epitheliomas or malignant melanomas. In any case, such lesions require a generous and full-thickness excision, usually with frozen sections. Inadequate primary excision of the deeper structures occurs far too frequently and, once the first opportunity for complete excision has been lost, the patient may return time after time with further recurrences [9].

Reconstructive techniques can be classified considering the anatomical area requiring treatment: superior eyelid, inferior eyelid, and inner or external canthus [811]. Simplifying, we can distinguish [10]: (1) direct suture, (2) grafts, and (3) flaps.

By definition, a skin flap differs from a skin graft because it consists not only of skin but also of subcutaneous tissue with its subdermal plexus of vessels. Although it is completely raised from the underlying tissue, it is still connected by at least one side to the surrounding skin and fat. It is because of the vessels contained in this pedicle that the flap can preserve its own blood supply, independent of the site on which it is placed.

We can classify grafts according to their thickness [8]. The most frequently used graft is the Wolfe-Krause graft $(0.80-1.00 \mathrm{~mm})$, taken from the skin with a scalpel. Other grafts are the thin-skin grafts, such as the Ollier-Thiersh graft $(0.20-0.35 \mathrm{~mm})$, and the middle-thickness grafts such as the Blair-Brown $(0.40-0.60 \mathrm{~mm})$ or Padgett $(0.60-0.80 \mathrm{~mm})$ grafts. Both thin-skin and middle-thickness grafts can only be taken with the use of a dermatome $[6,8]$. 


\section{Case Report}

A 79-year-old woman presented to the Ophthalmic Hospital in Turin with a history of progressive neoformation of the upper eyelid. She was monitored by her consultant for some months and finally referred to our attention.

We performed a biopsy and diagnosed basal cell carcinoma of the upper eyelid, involving the border along two-thirds of the length, with initial erosion (fig. 1). In this type of basal cell carcinoma, a wide and full-thickness primary excision of the tumor is extremely important. A local anesthetic was slowly injected into the subcutaneous and submuscular layer. In order to give excellent anesthesia and reduce bleeding, 50\% Naropin $7.5 \mathrm{mg} / \mathrm{ml}$ and 50\% Carbocaine with epinephrine 1:200,000 were used. A full-thickness excision of the whole lesion was performed, with a margin of normal skin of at least $4 \mathrm{~mm}$. Bleeding points were controlled using bipolar radiofrequency. Then, four permanent sections of $1 \mathrm{~mm}$ around the border of the excision, one laterally, one medially and two superiorly, were taken. This was done in order to have a histological clearance rate and a localization of a possible inadequate excision.

In this case, the decision was taken to proceed to immediate reconstruction, in part because the patient had been placed in a high anesthesiological risk class, plus a safe and wide excision could be performed due to the clear definition of the tumor borders, localized in the eyelid margin. In order to reconstruct the eyelid, a tarsal-conjunctival graft from the contralateral deep lamella of the upper eyelid was used (the excision area did not require suturing). The graft had to be sutured to the area of the tumor excision with 6.0 vicryl. It is important to connect the superior edge of the graft to the residues of the levator aponeurosis, to guarantee the best functional result.

The graft was recovered and vascularized with a bipedicled flap obtained from the ipsilateral eyelid. In order to cover the cutaneous gap left after the flap was obtained, we decided to use a cutaneous graft taken from the contralateral upper eyelid again. A superficial excision of skin, as for an upper lid blepharoplasty, was performed, followed by a 6.0 silk suture. The graft was thinned with a clamp and dissecting scissors, in order to remove the subcutaneous and fatty tissue, then carefully sutured to the area that had to be covered ( $\underline{\mathrm{fig} .} 2$ ). When closing the graft, suture wires (we used 5.0 silk) must be kept quite long in order to use them to fix a little bow of gauze as a final medication (fig. $\underline{3}$ ). It is important to apply pressure to the graft to immobilize and fix it. To this end, a gauze pad with hyaluronic acid was prepared, creating a little bow. The gauze pad was knotted using the long suture wires, as described above, creating a compression on the donor site. Finally, everything was covered with another medicated gauze pad. We believe that this pressure dressing is very important for the survival of the graft. The bow was removed after 5 days and replaced with a non-medicated gauze pad for another 3 days.

The upper eyelid is a structure that requires careful consideration during reconstruction, mainly because of its role in protecting the corneal tissue. It is extremely important that the surgeon personally follows up the medication of the grafts after surgery.

The reconstruction technique should be customized to the individual patient. In this case, the use of a full-thickness tarsal graft from the contralateral upper eyelid, followed by an ipsilateral bipedicled flap and finally by a skin graft, was an effective surgical procedure for at least 3 reasons: (1) the procedure is very safe and can be performed in one stage. We did not encounter postoperative complications. Anatomopathological service confirmed the diagnosis of basal cell carcinoma and the complete absence of tumor infiltration in the examined tissue margins and permanent sections. (2) A good functional result was obtained. Eyelid function after surgery was excellent. To indirectly evaluate the function of the eyelid, the ocular surface disease index [12], tear breakup time and Schirmer's test were evaluated 3 months after surgery. An ocular surface disease index score of 80 was obtained. Tear breakup time and Schirmer's test results were $9 \mathrm{~s}$ and $14 \mathrm{~mm}$, respectively, in the ipsilateral eye, and $10 \mathrm{~s}$ and $13 \mathrm{~mm}$, respectively, in the contralateral eye. Furthermore, fluorescein and lissamine green tests demonstrated poor staining. (3) A good esthetic result was obtained (fig. 4). 


\section{Discussion}

Basal cell carcinoma typically affects patients over the age of 60 years. It is the most common skin cancer in white populations with an increasing incidence worldwide, thereby imposing an important public health problem. Its etiology is still unclear, but existing data indicate that the risk for its development is of multifactorial origin and results from both constitutional and environmental factors. Yet, UV radiation is believed to be the predominant causative risk factor in the pathogenesis of basal cell carcinoma [2-4]. It frequently occurs in the periocular region (eyebrows, glabella, ocular canthi, eyelids and subpalpebral region) [10]. Approximately $5-10 \%$ of all skin cancers occur in the eyelid [3]. Considering epithelial tumors ( $90 \%$ of malignant eyelid tumors), basal cell carcinoma is much more frequent if compared to squamous cell carcinoma (40/1). In 59\% of patients, epithelial tumors affect the lower eyelid, in $22 \%$ the inner canthus, in $14 \%$ the superior eyelid and in 5\% the external canthus [13].

Basal cell carcinoma can have pleomorphic clinical manifestations [6, 10, 14]. It tends to grow vertically in the various cutaneous folds and furrows, especially at the ocular medial canthus. Involvement of the edge of the eyelid with invasion of the conjunctival sac or even of the eye is not exceptional. As in the case of basal cell cancer of other areas, it is not easy to establish a correlation between the histological features or clinical manifestations and the invasiveness of the tumor. The initial lesion may be simply erythematous or erythematous desquamative (erythematous basal cell carcinoma), usually characterized by slightly elevated translucent borders. 'Bowenoid' or 'pagetoid' basal cell carcinomas are characterized by more marked scaling, crusting and exudating areas. The affected area may be infiltrated, with a cicatricial or sclerodermiform appearance and well-defined borders (sclerodermiform basal cell carcinoma). In other cases, the sclerosis, the atrophic changes and the expanding borders of the tumor are poorly defined (cicatricial basal cell carcinoma). These cases are quite difficult to treat and frozen sections or Mohs technique are fundamental. Ulcus rodens is another type of basal cell carcinoma, with ulceration and progressive vertical growth. Basal cell carcinoma of the eyelid edge presents as a nodule that may ulcerate or as a primary erosion. Nodular basal cell carcinoma is characterized by a rounded, elevated, translucent tumor that may exceed $1 \mathrm{~cm}$ in length. Flat and nodular basal cell carcinomas are often pigmented.

The patient treated in this case report had a primary erosion of the superior eyelid edge, with well-delimited borders of the lesion. A very large and full-thickness excision of the tumor is always necessary [14]. The surgical technique must be individualized for each patient and for each type of basal cell carcinoma. Reconstructive techniques with free grafts and flaps yield excellent esthetic and functional results in the orbital region if the rules that condition good graft attachment are respected: accurate hemostasis of the receiving bed by moderate use of diathermy; careful suture of the edges; application of a compressive roll of gauze for at least 4 days. Furthermore, it is advisable that the graft surface is $1 / 3$ wider than that of the area to be covered, especially in cases of scar retraction. This local bipedicled flap minimizes the risk of necrosis because it has a double-random pattern blood supply in a highly vascularized area. In similar cases when there is an upper lid marginal defect - particularly when enough tarsus remains - the first-choice technique (local advancement flaps) has been reported by Irvine and McNab [15]. 
In this case report, the excision of the tarsal plate was wider than we had planned. About $2 \mathrm{~mm}$ of tarsus were remaining, a perfect situation for a tarsal graft of about 4 $\mathrm{mm}$ in height. In other cases, when a wider and higher part of the upper lid must be excised, the Cutler-Beard or the Mustardé technique could be used [9]: both are 2-stage procedures.

In conclusion, we must admit that the use of free grafts and flaps is well known in the literature. However, this case report underlines the importance of the skin graft to cover the wide deficit of skin. This allows the mobilization of a wide bipedicled flap, thick enough to allow good vascularization of the central part of the flap itself and of the underlying cartilage [10].

\section{Disclosures}

None of the authors have any proprietary interests or conflicts of interest related to this work. No financial support was received for this study. This submission has not been published anywhere previously or presented at any congress. It is not simultaneously being considered for any other publication.

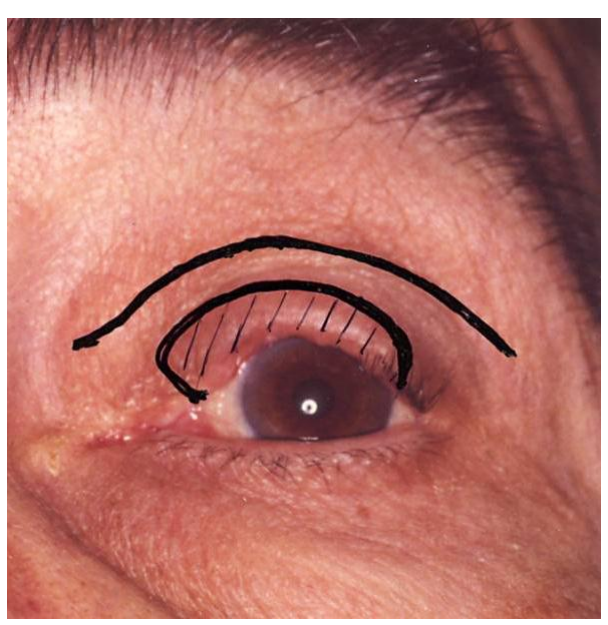

Fig. 1. Basal cell carcinoma of the superior eyelid margin. 


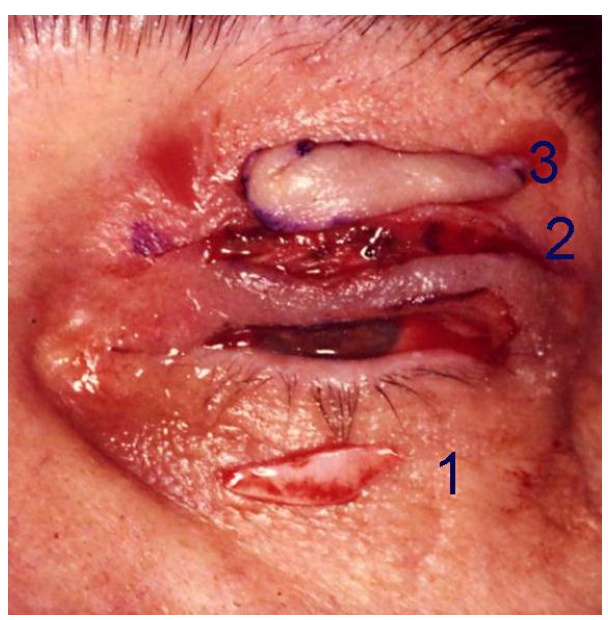

Fig. 2. Grafts and flap. 1 Contralateral tarsal-conjunctival graft. 2 Bipedicled flap (hiatus remained after moving the flap down to cover the area). 3 Cutaneous graft from the contralateral eyelid.

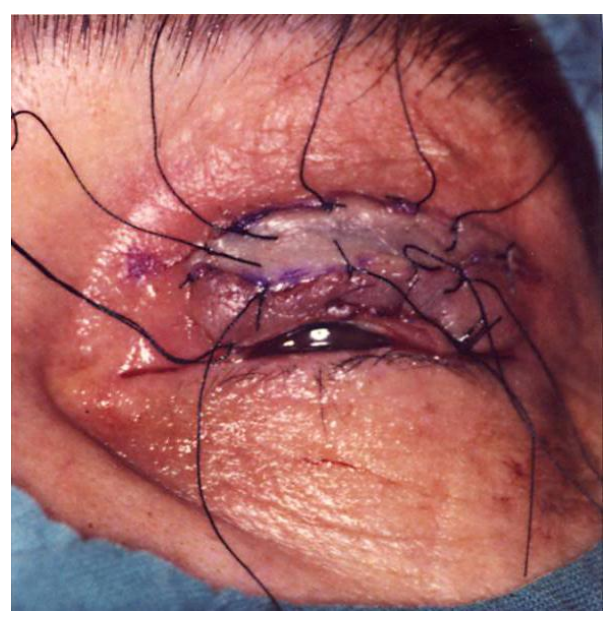

Fig. 3. Result at the end of the surgical procedure, before medication. 


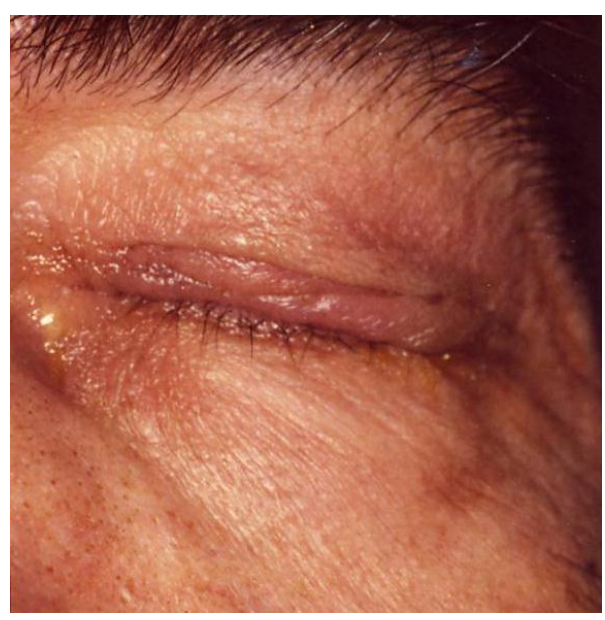

Fig. 4. Result 3 months after surgery.

\section{References}

1 Older JJ: Eyelid Tumors: Clinical Diagnosis and Surgical Treatment, ed 2. London, Manson Publishing, Ltd., 2003.

-2 Dessinioti C, Antoniou C, Katsambas A, Stratigos AJ: Basal cell carcinoma: what's new under the sun. Photochem Photobiol 2010;86:481-491.

-3 Cook BE Jr, Bartley GB: Epidemiologic characteristics and clinical course of patients with malignant eyelid tumors in an incidence cohort in Olmsted County, Minnesota. Ophthalmology 1999;106:746-750.

$\checkmark 4$ Cook BE Jr, Bartley GB: Treatment options and future prospects for the management of eyelid malignancies: an evidence-based update. Ophthalmology 2001;108:2088-2098.

5 Actis AG, Actis G, Amidei A, Buschini E, Nuzzi R: Escissione della neoformazione palpebrale: approccio metodologico, didattico, preventivo. Minerva Oftalmol 2009;51:113-118.

6 6 Leibovitch I, Selva D, Davis G, Ghabrial R: Donor site morbidity in free tarsal grafts. Am J Ophthalmol 2004;138:430-433.

7 Manstein ME, Manstein CH, Smith R: How accurate is frozen section for skin cancers? Ann Plast Surg 2003;50:607-609.

-8 Bernardini FP: Management of malignant and benign eyelid lesions. Curr Opin Ophthalmol 2006;17:480-484. Review.

9 Mustardé JC: Repair and Reconstruction in the Orbital Region. A Practical Guide, ed 2. Edinburgh, Churchill Livingstone, 1980.

10 Actis G, Malinverni W, Kuba I: Free grafts in the orbital region. Panminerva Med 1987;29:61-63.

11 Ferguson NM, Mathijssen IM, Hofer SO, Mureau MA: Decision making in reconstruction of defects of the eyelid. J Plast Surg Hand Surg 2011;45:45-50.

12 Schiffman RM, Christianson MD, Jacobsen G, Hirsch JD, Reis BL: Reliability and validity of the Ocular Surface Disease Index. Arch Ophthalmol 2000;118:615-621.

13 Loeffler M, Hornbass A: Characteristics and behavior of eyelid carcinoma (basal cell, squamous cell sebaceous gland, and malignant melanoma). Ophthalmic Surg 1990;21:513-518.

14 Tyers AG, Collin JRO: Colour Atlas of Ophthalmic Plastic Surgery, ed 2. Oxford, Butterworth Heinemann, 2001.

15 Irvine F, McNab AA: A technique for reconstruction of upper lid marginal defects. Br J Ophthalmol 2003;87:279-281. 